\title{
Correlation between Processing, Morphology and Impact Resistance of PBT/ABS Blends
}

\author{
André Cortegoso Prezenszky", José Donato Ambrósio ${ }^{a, b} *$, Luiz Antonio Pessan ${ }^{c}$, Elias Hage Jr. ${ }^{c}$ \\ ${ }^{a}$ Pós-Graduação em Engenharia de Materiais e Ciências - PPGCEM, Departamento de Engenharia \\ de Materiais - DEMa, Universidade Federal de São Carlos - UFSCar, Via Washington Luiz Km 235, \\ 13565-905, São Carlos, SP, Brazil \\ ${ }^{b}$ Centro de Caracterização e Desenvolvimento de Materiais - CCDM, Departamento de Engenharia \\ de Materiais - DEMa, Universidade Federal de São Carlos - UFSCar, Via Washington Luiz Km 235, \\ 13565-905, São Carlos, SP, Brazil \\ ${ }^{c}$ Departamento de Engenharia de Materiais - DEMa, Universidade Federal de São Carlos - UFSCar, \\ 13565-905, São Carlos, SP, Brazil
}

Received: December 08, 2016; Revised: March 27, 2017; Accepted: September 15, 2017

To understand the processing influence in an intermeshing corotating twin-screw extrusion (ICTSE) on the morphology and impact properties of the uncompatibilized PBT/ABS (70/30) blend, it was submitted to different processing parameters. In this way both morphology and impact properties (resistance and ductile brittle transition temperature (DBTT) would be a function of processing only, because there would be no influence of a compatibilizer. The rotation speed of the screws influenced both impact resistance and Ductile Brittle Transition Temperature (DBTT) of the PBT/ABS blends. Blends prepared with higher rotation speed $(240 \mathrm{rpm})$ did not present toughness at room temperature, whereas the blends prepared at lower speed showed high impact strength at room temperature and DBTT near to $5{ }^{\circ} \mathrm{C}$. The angle between the kneading blocks discs also influenced the impact properties, because blends processed with screw with $90^{\circ}$ angle between kneading block disks, for two different feed rates, showed lower DBTT than the blends processed with $45^{\circ}$ angle. The morphological analysis by TEM showed that blends processed at low rotation speed of the screws presented a higher dispersion degree than those processed at high rotation speed. Blends processed in screws where the angle between the disks was $90^{\circ}$ showed a higher dispersion degree than the blends processed in disks with a $45^{\circ}$ angle. These results are in agreement with the impact properties, confirming that high dispersion of the ABS particles improves the impact properties of the blend.

Keywords: PBT/ABS blends, twin screw extruder, morphology, impact resistance.

\section{Introduction}

Preparation of polymer blends appeared as an alternative to the development of new polymeric systems to achieve different properties from those obtained by existing polymers or copolymers. Mixture of polymers allows the combination of properties of the blend's constituent polymers, to achieve one or more desired properties. One of the applications of polymer blends is to promote the toughness of brittle polymers. In this case, the modified polymer is mixed with another with a high deformation capacity, such as elastomers, thermoplastic rubbers or others modified thermoplastics.

The main mixing process of polymer blends occurs in the molten state, and the processing in twin screw extruders has been more appropriate for both productivity and mixing quality. Twin-screw extruders operate as continuous intensive mixers and the screws can be cylindrical or conical, co-rotational or counter-rotational and intermeshing or not. During the processing in the twin-screw extruders the polymers are usually subjected to various types of flow (shear, elongational or both) in the screw (kneading blocks) and in the extrusion die.

*e-mail: donato@ccdm.ufscar.br
During the mixing of polymer blends breaking and coalescence of the dispersed phase occur according to parameters such as viscosity ratio of the polymers, shear stress, interfacial tension, adhesion, shear rate, melt elasticity and composition. These factors determine the morphology and hence the final properties of the blend. Therefore, the final morphology of the blend depends on the physicochemical characteristics of the polymers, rheological properties and process parameters used during the mixing. As extrusion in twin-screw is a complex process, analysis of the influence of the process parameters on the morphology and final properties is also complex and least investigated of simple polymeric systems.

Poly (butylene terephthalate) (PBT) is a semi-crystalline polyester with excellent properties such as high stiffness and hardness, abrasion and solvents resistance and rapid crystallization. Despite of these good characteristics, the PBT is notch sensitivity, what leads to a brittle fracture mode when notched specimens are submitted to impact tests. The PBT toughening can be obtained by adding the acrylonitrilebutadiene-styrene copolymer (ABS), which is a thermoplastic 
modified with rubber. In this sense, the blend of PBT/ABS has been extensively studied ${ }^{1-8}$. This blend has a high impact resistance when tested with notch at room temperature, but brittle behavior at low temperatures. PBT/ABS (70/30) blend compatibilized in situ with the terpolymer methyl methacrylate-glycidyl methacrylate-ethyl acrylate (MGE) presents high impact resistance at low temperature. PBT/ ABS blend was studied to verify the influence of the process parameters on the morphology and end properties ${ }^{7-10}$. The results were very satisfactory and MGE stabilized morphology of the blend preventing coalescence of the dispersed phase, but partially reducing the influence of process parameters on the morphology of the blend. In addition to MGE, others compatibilizers were studied to stabilize the morphology of the PBT/ABS blend ${ }^{11-13}$.

Thus, this study aims to evaluate the phase morphology in uncompatibilized PBT/ABS blends, because the compatibilizer minimizes the influence of the process parameters on morphology and the end properties of the blend. This occurs because the reactive compatibilizer quickly stabilizes the morphology, and the breaking and coalescence processes are not affected by the processing.

\section{Experimental}

\subsection{Materials and Processing}

The polymers used in the PBT/ABS blend were the polybutylene terephthalate (PBT) and the ABS terpolymer, commercially known as Valox 315 and Cycolac 36360, respectively. This PBT has a melt flow index of $6.3 \mathrm{~g} / 10$ min when measured at $250^{\circ} \mathrm{C}$ under a load of $1.20 \mathrm{Kg}$. ABS obtained by emulsion polymerization was quantitatively characterized by Fourier transform infrared spectrometry and presented $51 \mathrm{wt} \%$ butadiene, $36 \mathrm{wt} \%$ styrene, and 13 $w t \%$ acrylonitrile. Sabic Innovative Plastics South America has provided both materials.

PBT and ABS present very different rheological characteristics. One way to verify its rheological characteristics is to determine the pseudoplasticity index (n) related to the deviation Newtonian behavior, and the consistency parameter (m), which corresponds to the shear stress when the shear rate is extrapolated to $1 \mathrm{~s}^{-1}$, and therefore represents the polymer viscosity for shear rate equal to unity. Thus, capillary rheometry analyzes were performed in a rheometer INSTRON model 4467 at 250 and $275^{\circ} \mathrm{C}$, with a capillary die, where $\mathrm{D}=$ $0.76 \mathrm{~mm}$ and $\mathrm{L} / \mathrm{D}=33$ in shear rates ranging from 100 to $4,000 \mathrm{~s}^{-1}$. Table 1 shows that the pseudoplasticity index for PBT was 0.73 at $250{ }^{\circ} \mathrm{C}$ and 0.81 at $275^{\circ} \mathrm{C}$, while for the ABS it was 0.20 at $250^{\circ} \mathrm{C}$ and 0.24 at $275^{\circ} \mathrm{C}$. PBT presents a behavior very close to the Newtonian, while the ABS a strong pseudoplastic behavior. Regarding the viscosity was observed that for PBT the $\mathrm{m}$ values are $477 \mathrm{~Pa} . \mathrm{s}^{\mathrm{n}}$ at $250^{\circ} \mathrm{C}$ and $117 \mathrm{~Pa} . \mathrm{s}^{\mathrm{n}}$ at $275^{\circ} \mathrm{C}$, while for $\mathrm{ABS}$ the $\mathrm{m}$ values are
69,116 and 46,907 Pa. $\mathrm{s}^{\mathrm{n}}$, respectively. This is a difference of about two orders of magnitude. The high value of $m$ for ABS was expected for polymers with high rubber content.

Thus, in order to primarily enhance the notched impact resistance of the neat PBT (Valox 315), the PBT/ABS blend was prepared by adding $30 \mathrm{wt} \%$ of the ABS terpolymer (Cycolac 36360), which contains high content of polybutadiene rubber.

The uncompatibilized PBT/ABS blends were prepared on the proportions of PBT/ABS (70/30), and mixed in a $30 \mathrm{~mm}$ diameter and $\mathrm{L} / \mathrm{D}=35$ Werner-Pfleiderer ICTSE using the screw profiles shown in Figure 1. The blends were extruded through an extrusion die with rectangular section of $25.00 \mathrm{x}$ $3.60 \mathrm{~mm}$ and lands with 2.00 and $62.00 \mathrm{~mm}$. A mini-channel apparatus was positioned at the end of the extruder to help cooling the extruded ribbons ${ }^{8}$. All screw profiles exhibit two kneading blocks type KB45/5/42 at the fourth barrel of the extruder, to melt PBT before the addition of ABS on the fifth barrel of the extruder through a side feeder. The PBT was in the form of pellets, while ABS was in the form of powder. The four kneading blocks type KB45/5/42, KB45/5/14 or KB90/5/14 located at the end screws were responsible for the mixing of the blend components. The thermal profile along the extruder was $260 / 270 / 240 / 240 / 240{ }^{\circ} \mathrm{C}$ and the temperature at the extrusion die was $240^{\circ} \mathrm{C}$. Thus, to verify the influence of the extrusion processing on the morphology and impact resistance of the PBT/ABS blends, the following process parameters were investigated: a) screws speed (120 and $240 \mathrm{rpm}), \mathrm{b}$ ) extrusion die land (2.00 and $62.00 \mathrm{~mm})$, c) angle between the kneading blocks disks $\left(45^{\circ}\right.$ and $\left.90^{\circ}\right)$ and d) feed rate $(3.50$ and $7.00 \mathrm{~kg} / \mathrm{h})$.

\subsection{Testing and Characterization}

Notched Izod impact testing was performed in extruded ribbons according to ASTM D256 at -40, -20, -15, -10, -5, 0, $5,10,15,20,25$ and $30^{\circ} \mathrm{C}$ to determine the impact resistance and the Ductile Brittle Transition Temperature (DBTT) of the blends. The equipment used was a Ceast model Resil 25 pendulum and at least six specimens of each sample were tested in each temperature. After the camera reached the equilibrium temperature, the samples were maintained for at least 15 minutes before beginning the test.

Transmission electron microscopy (TEM) investigated the center of the cross-section of the samples of extruded ribbons in the region perpendicular to the flow of molten polymer. The samples were cut in an ultramicrotome [Reichert-Jung (Leica) UltraCut S] and stained with the vapor of an aqueous solution of osmium tetroxide for $24 \mathrm{~h}$. In this chemical etching the butadiene double bonds in the ABS are oxidized by the osmium tetroxide. The morphology of the blends was examined in a TEM (Phillips CM120), at an accelerating voltage of $120 \mathrm{kV}$. After obtaining the micrographs, the dispersion of the ABS particles was analyzed through binarization of the images using the software Image Pro Plus 
Table 1. Rheological characteristics of PBT and ABS obtained with capillary rheometer at temperatures of 250 and $275^{\circ} \mathrm{C}$.

\begin{tabular}{|c|c|c|c|c|}
\hline \multirow{2}{*}{ Polymer } & \multicolumn{2}{|c|}{ Temperature at $250^{\circ} \mathrm{C}$} & \multicolumn{2}{|c|}{ Temperature at $275^{\circ} \mathrm{C}$} \\
\hline & $\mathbf{n}$ & $\mathbf{m}\left[\mathbf{P a} . \mathbf{s}^{\mathrm{n}}\right]$ & $\mathbf{n}$ & m [Pa.s $\left.{ }^{n}\right]$ \\
\hline ABS - Cycolac 36360 & 0.20 & 69,116 & 0.24 & 46,907 \\
\hline PBT - Valox 315 & 0.81 & 477 & 0.73 & 117 \\
\hline
\end{tabular}

Where: $\mathrm{n}=$ pseudoplasticity index and $\mathrm{m}=$ consistency parameter

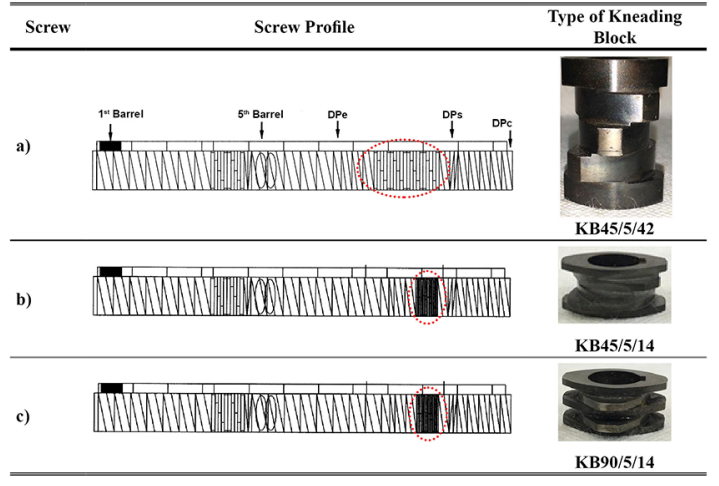

Figure 1. Twin screw profiles with four kneading blocks of five discs positioned in the mixing zone between two pressure transducers (DPe e DPs), where: a) screw $4 \mathrm{~KB} 45 / 5 / 42$, b) screw $4 \mathrm{~KB} 45 / 5 / 14$ and c) screw 4KB90/5/14.

3.0, Media Cybernetics. Thus, ABS dispersion was evaluated by measures obtained from the binarized micrographs and the values entered in Equation 1, to calculate a dispersion function. Equation 1 deals with the total number of ABS particles (n) and the total area of these particles. However, as ABS particles had irregular shapes, there is a second term in equation 1 that is the quotient of the particles perimeter sum by sum of the areas of these particles 5 .

Dispersion function $=\frac{(n)}{\sum \text { Total area }} \times \frac{\sum \text { Perimeter } A B S}{\text { AreaABS }}$

\section{Results and discussions}

Previous studies ${ }^{3}$ with the PBT/ABS (70/30) blend showed that even without the use of the MGE compatibilizer, the ABS increased the impact resistance at room temperature by approximately fifteen times, when compared to neat PBT. Figure 2 shows the influence of the rotation speed of the screw 4KB45/5/42 on the impact resistance and DBTT of the PBT/ABS blend. The samples were obtained by extrusion with dies with same cross-section but different extrusion die lands (2.00 and $62.00 \mathrm{~mm})$. It is observed that a significant influence occurred in both impact resistance and in the DBTT, as function of the rotation speed of the screws. Figure 2 shows that blends prepared with higher rotation speed $(240 \mathrm{rpm})$ did not present toughness at room temperature, while blends prepared at lower speed presented high impact strength at room temperature and DBTT near 5 ${ }^{\circ} \mathrm{C}$. It is also observed that the impact resistance was much
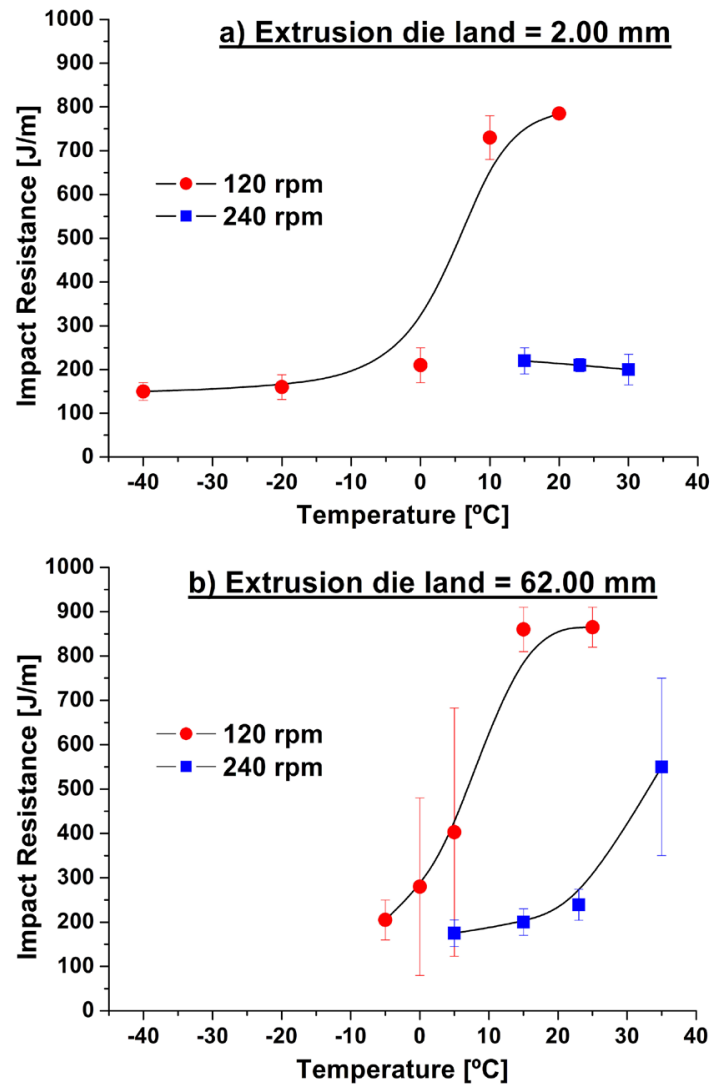

Figure 2. Influence of the rotation speed of the screw 4KB45/5/42 on the impact resistance and DBTT of the PBT/ABS blends with extrusion dies which lengths were a) die land of $2.00 \mathrm{~mm}$ and $\mathrm{b}$ ) die land of $62.00 \mathrm{~mm}$.

lower in the blends processed at higher speed for extrusion dies with different lengths.

High rotation speeds also provide higher shear rates on the PBT/ABS blend. The ABS (Cycolac 36360) contains $50 \%$ of polybutadiene and exhibits a high pseudoplastic behavior with flow index (n) of 0.20 at $250{ }^{\circ} \mathrm{C}^{8}$. Polymers with low flow index reduce the viscosity more rapidly with increased shear rate, and therefore better conditions can be generated for the dispersive and distributive mixtures of the dispersed phase. However, this behavior was not observed probably due to degradation of the PBT matrix, which would have greatly reduced its viscosity. Thus, with the possible degradation of the PBT matrix, its viscosity reduced already during processing, allowing greater coalescence of the ABS. The blend toughness is also influenced causing lower impact 
resistance even at room temperature. The blend obtained at $240 \mathrm{rpm}$ and long extrusion die $(62.00 \mathrm{~mm})$ showed higher impact resistance at $30^{\circ} \mathrm{C}$ than the one prepared in the same rotation speed but with smaller extrusion die $(2.00 \mathrm{~mm})$. This higher impact resistance can be due to alignment of polymer chains in the extrusion die, and the rapid cooling when the blend left the die. Thus, an increase in impact resistance could occur because the impact test was performed at $90^{\circ}$ from the of the extrusion flow direction.

The angle between the kneading blocks discs also influenced the DBTT and impact resistance of the PBT/ ABS blends. Blends processed with screw 4KB90/5/14 $\left(90^{\circ}\right)$ in two feed rates showed lower DBTT than the blends processed with the screw $4 \mathrm{~KB} 45 / 5 / 14\left(45^{\circ}\right)$. Figure $3 \mathrm{~b}$ shows that the blends with the lowest DBTT $\left(-5^{\circ} \mathrm{C}\right)$ were obtained with the screw $4 \mathrm{~KB} 90 / 5 / 14$ and feed rate of $7.0 \mathrm{~kg} / \mathrm{h}$. The best result of impact resistance was obtained with the screw $4 \mathrm{~KB} 45 / 5 / 14$ and feed rate of $3.5 \mathrm{~kg} / \mathrm{h}$, but the DBTT was 5 ${ }^{\circ} \mathrm{C}$. In this case, two combined effects were evaluated: the angle between the kneading blocks disks and the feed rate of the PBT/ABS blend.

With respect to the angle between the disks, when it is $90^{\circ}$ the flux of the melt blend inside screw is practically null when compared to the angle of $45^{\circ}$. This occurs because, with $90^{\circ}$, the melt blend does not advance forward due to the
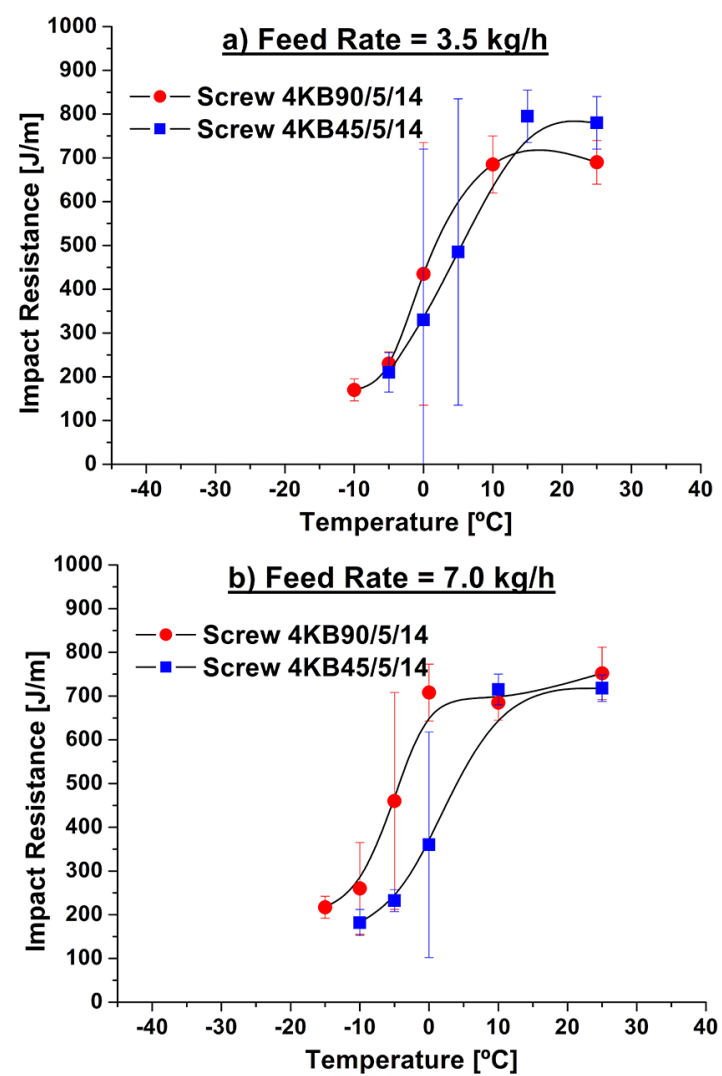

Figure 3. Influence of the angle between the kneading blocks discs in the ICTSE mixing zone on the impact resistance and DBTT of PBT/ ABS blends obtained with feed rates of a) $3.5 \mathrm{~kg} / \mathrm{h}$ and b) $7.0 \mathrm{~kg} / \mathrm{h}$. movement of the discs. In this way, in the kneading blocks where the angle is $90^{\circ}$, the blend was sheared for longer time than in the blocks where it is $45^{\circ}$. When the angle is $90^{\circ}$ the path of the melt blend in the direction of the extrusion die occurs with the arrival of the new material that has been fed, which pushes the blend forward. Thus, although the $90^{\circ}$ angle has a higher mixing efficiency, it can also lead to polymer degradation by very intense shear. Another process parameter investigated was the feed rate of the blend components. Lower feed rates of the blend components resulted in the emptying of the screw, thus increasing the residence time. This makes the blend to be mixed for longer time, but there is a possibility of degradation of the polymers. In this way, the blend processed with $3.5 \mathrm{~kg} / \mathrm{h}$ and angle of $90^{\circ}$ between the kneading blocks disks presented the worst impact resistance. The blend that presented the best result for the two impact properties was the one processed with $7.0 \mathrm{~kg} / \mathrm{h}$ and $90^{\circ}$ angle between kneading blocks disks.

The possibility of degradation at low feeding rate and higher screw speed was investigated with a MGE-compatible $\mathrm{PBT} / \mathrm{ABS}$ blend ${ }^{10}$. This study evaluated the effect of extrusion conditions and the use of a compatibilizer in the crystallization of PBT/ABS blends. It was observed that when the blends were submitted to these conditions they presented a higher crystallinity degree obtained by differential scanning calorimetry (DSC), and lower viscosity evaluated with capillary rheometry ${ }^{10}$. Blends processed with low feeding rate remain longer inside the extruder and therefore subjected to higher shear that could lead to PBT rich phase molecular degradation, which usually occurs by chain scission ${ }^{14}$. In this way, PBT short chains would have higher mobility to crystallize at higher crystallinity content. These same blends prepared with low feeding rate shown a strong decrease in the viscosity values comparing with blends obtained with higher feeding rates. The reduction of viscosity is a strong evidence of the blend degradation, which confirms the supposing PBT rich phase degradation observed in the DSC due to the increase in heat of fusion. Therefore, a possible degradation of the PBT chains would lead to a decrease in the size of their chains and in the viscosity of the blend. As a result could occur increase in crystallinity and a reduction in impact properties. For the decrease in the impact properties with increased rotation speed, the degradation could occur by the increase of the shear rate and of the heat generated by the viscous friction ${ }^{10}$.

The characteristic morphology of the non-compatibilized PBT/ABS blends is shown in Figure 4, where the dark regions are the dispersed phases of the ABS. It is observed that a low breaking of the agglomerates into smaller particles occurred, showing that the breaking and coalescence process entered into equilibrium, and the smaller particles were not completely separated. In the PBT/ABS (70/30) blends compatibilized with MGE, the separation in smaller particles was clearly verified ${ }^{6-8}$. 

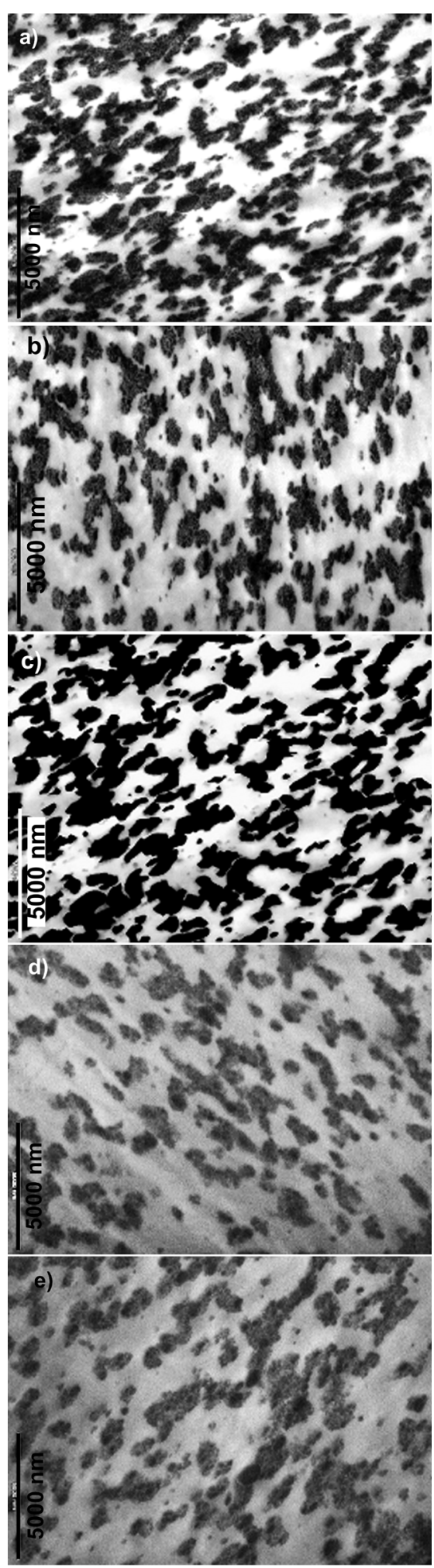

Figure 4. Micrographs obtained by TEM from PBT/ ABS blend processed with screw $4 \mathrm{~KB} 45 / 5 / 42$ and $7.0 \mathrm{~kg} / \mathrm{h}$, where: a) Sample $120 \mathrm{rpm}$ and die with $2.00 \mathrm{~mm}$, b) Sample $240 \mathrm{rpm}$ and die with $2.00 \mathrm{~mm}$ c) Sample a) binarized for dispersion calculation, d) Sample $120 \mathrm{rpm}$ and die with $62.00 \mathrm{~mm}$ and e) Sample $240 \mathrm{rpm}$ and die with $62.00 \mathrm{~mm}$.
Table 2 shows that the blends processed at $120 \mathrm{rpm}$ presented a higher dispersion degree than those processed at $240 \mathrm{rpm}$. This result is in agreement with the verified behaviors for the impact resistance of these samples. Lower shear rates in the blends processed at $120 \mathrm{rpm}$ led to better conditions for the development of a morphology where the ABS particles were more dispersed. This is possibly related to lower degradation of the PBT matrix at low screw speeds, which favored particle breakage and hindered coalescence.

Table 2. Dispersion degree of the ABS particles in the PBT matrix as function of the rotation speed of the screws and extrusion die land, obtained with screw KB45/5/42 and feed rate of $7.0 \mathrm{~kg} / \mathrm{h}$.

\begin{tabular}{ccc}
\hline Rotation speed $[\mathrm{rpm}]$ & $\begin{array}{c}\text { Die land } \\
{[\mathrm{mm}]}\end{array}$ & $\begin{array}{c}\text { Dispersion degree } \\
{\left[\text { unit/mm } / \mathrm{mm}^{3}\right]}\end{array}$ \\
\hline 120 & 2.00 & 4.5 \\
240 & 2.00 & 3.8 \\
120 & 62.00 & 3.5 \\
240 & 62.00 & 2.4 \\
\hline
\end{tabular}

The influence of the extrusion die land is observed by comparisons in Table 2, where the blends were obtained with the same screw speed, but extrusion die lands of 2.00 and $62.00 \mathrm{~mm}$. Blends obtained with extrusion die land of 2.00 $\mathrm{mm}$ presented better dispersion, for two rotation speeds. These results are in agreement with the impact properties and may be related to two causes. The first would be because the longer die increases the pressure and hence the residence time of the blend within the extruder. This could lead to degradation of the PBT with reduction of its viscosity and to the easier coalescence of the ABS. The second cause would be due to the elongational flow occurring at the entrance of the extrusion die. This flow is more efficient for particle breakage than the shear flow within the extrusion die land. In this case, the probable morphology developed at the entrance of the die would be destroyed in the die with larger land (62.00 $\mathrm{mm}$ ), thus promoting the coalescence of the particles. The morphology due to the elongational flow would remain for blends processed with shorter extrusion die lands $(2.00 \mathrm{~mm})$. This could occur because the residence time is low and the blend was cooled with water at the die exit.

Table 3 shows the influence of the angle between the disks on the dispersion of the ABS particles at two feed rates. It is observed that with feed rate of $7.0 \mathrm{~kg} / \mathrm{h}$ and screw $4 \mathrm{~KB} 90 / 5 / 14\left(90^{\circ}\right)$ the dispersion degree was significantly higher than with the screw $4 \mathrm{~KB} 45 / 5 / 14\left(45^{\circ}\right)$. These results are in agreement with the previously discussed impact properties showing that the higher dispersion of the ABS particles increases the blend impact properties. That is, when the blend was processed with a $90^{\circ}$ angle between the discs, it did not advance forward, and therefore it was more sheared than the blends processed with a $45^{\circ}$ angle between the discs. This could improve the dispersion of ABS in the PBT matrix. However, this effect was not observed for the 
Table 3. Dispersion degree of the ABS particles in the PBT matrix as function of the angle between the kneading blocks disks and the feed rate of the blends, obtained with extrusion die land of $2.00 \mathrm{~mm}$ and speed rotation of 120 .

\begin{tabular}{ccc}
\hline Screw & $\begin{array}{c}\text { Feed rate } \\
{[\mathrm{kg} / \mathrm{h}]}\end{array}$ & $\begin{array}{c}\text { Dispersion degree } \\
{\left[\text { unit } / \mathrm{mm}^{3}\right]}\end{array}$ \\
\hline 4KB90/5/14 & 7,0 & 11,3 \\
$4 \mathrm{~KB} 45 / 5 / 14$ & 7,0 & 5,2 \\
$4 \mathrm{~KB} 90 / 5 / 14$ & 3,5 & 3,8 \\
$4 \mathrm{~KB} 45 / 5 / 14$ & 3,5 & 3,9 \\
\hline
\end{tabular}

blends processed at $3.5 \mathrm{~kg} / \mathrm{h}$, possibly because the feed rate was very low, increasing the residence time and degrading PBT matrix. Thus, the degradation could worsen the impact properties as observed in Figure $3 \mathrm{a}$.

\section{Conclusions}

Regarding to the process parameters, the rotation speed of the screws influenced both impact resistance and Ductile Brittle Transition Temperature (DBTT) of the PBT/ABS blends. Blends prepared with higher rotation speed (240 rpm) did not present toughness at room temperature, whereas the blends prepared at lower speed showed high impact strength at room temperature and DBTT near $5^{\circ} \mathrm{C}$. The angle between the kneading blocks discs also influenced the DBTT and impact resistance of the PBT/ABS blends. Blends processed with screw with $90^{\circ}$ angle between kneading block disks, for two different feed rates, showed lower DBTT than the blends processed with $45^{\circ}$ angle. The blend processed with $7.0 \mathrm{~kg} / \mathrm{h}$ and $90^{\circ}$ angle between kneading blocks disks was the one with best results for the two impact properties.

The morphological analysis by TEM showed that blends processed at low rotation speed of the screws presented a higher dispersion degree than those processed at high rotation speed. These results were in agreement with the behaviors observed for the impact properties of these samples. It was observed that, for the higher feed rate, the blends processed in screws where the angle between the disks was $90^{\circ}$ showed a higher dispersion degree than the blends processed in disks with a $45^{\circ}$ angle. These results also agreed with the impact properties, confirming that high dispersion of the ABS particles improves the impact properties of the blend.

\section{Acknowledgments}

The authors gratefully acknowledge the financial support of FAPESP (Brazil) for the development of this work.

\section{References}

1. Hage E, Hale W, Keskkula H, Paul DR. Impact modification of poly(butylene terephthalate) by ABS materials. Polymer. 1997;38(13):3237-3250. DOI: 10.1016/S0032-3861(96)00879-8
2. Hale WR, Pessan LA, Keskkula H, Paul DR. Effect of compatibilization and ABS type on properties of PBT/ABS blends. Polymer. 1999:40(15):4237-4250. DOI: 10.1016/S00323861(98)00670-3

3. Hale W, Lee JH, Keskkula H, Paul DR. Effect of PBT melt viscosity on the morphology and mechanical properties of compatibilized and uncompatibilized blends with ABS. Polymer. 1999;40(13):3621-3629. DOI: 10.1016/S0032-3861(98)00583-7

4. Hage E, Ferreira LAS, Manrich S, Pessan LA. Crystallization behavior of PBT/ABS polymer blends. Journal of Applied Polymer Science. 1999;71(3):423-430. DOI: 10.1002/(SICI)10974628(19990118)71:3<423::AID-APP8>3.0.CO;2-0

5. Ito EN, Pessan LA, Hage E Jr, Covas JA. Análise do desenvolvimento morfológico da blenda polimérica PBT/ABS durante as etapas de mistura por extrusão e moldagem por injeção. Polímeros. 2004;14(2):83-92. DOI: 10.1590/S0104-14282004000200011

6. Canto LB, Mantovani GL, Covas JA, Hage E Jr, Pessan LA. Phase morphology development during processing of compatibilized and uncompatibilized PBT/ABS blends. Journal of Applied Polymer Science. 2007;104(1):102-110. DOI: 10.1002/app.24518

7. Ambrósio JD, Larocca NM, Pessan LA, Hage E Jr. Influence of the process parameters of an intermeshing co-rotating twin screw extruder on the morphology and notched Izod impact strength of PBT/ABS/MGE blends. Polymer Engineering \& Science. 2010;50(12):2382-2391. DOI: 10.1002/pen.21761

8. Ambrósio JD, Pessan LA, Larocca NM, Hage E Jr. Influência das Condições de Processamento na Obtenção de Blendas PBT/ABS. Polímeros. 2010:20(4):315-321. DOI: 10.1590/ S0104-14282010005000051

9. Ambrósio JD, Hage E Jr. Effect of processing parameters on the mechanical properties of in situ compatibilized polybutylene terephthalate/ acrylonitrile-butadiene-styrene blends. Journal of Applied Polymer Science. 2012;124(4):2753-2765. DOI: 10.1002/app.35205

10. Ambrósio JD, Pessan LA, Otaguro H, Chinelatto MA, Hage E Jr. The effect of extrusion conditions and the use of a compatibilizer in the crystallization of PBT/ABS blends. Materials Research. 2013;16(6):1220-1228. DOI: 10.1590/ S1516-14392013005000123

11. Sun S, Tan Z, Zhou C, Zhang M, Zhang H. Effect of ABS grafting degree and compatibilization on the properties of PBT/ ABS blends. Polymer Composites. 2007;28(4):484-492. DOI: $10.1002 /$ pc. 20318

12. Sun SL, Xu XY, Yang HD, Zhang HX. Toughening of poly(butylene terephthalate) with epoxy-functionalized acrylonitrile-butadienestyrene. Polymer. 2005;46(18):7632-7643. DOI: 10.1016/j. polymer.2005.06.011

13. Yao Z, Lin M, Zhou J, Wang H, Zhong W, Du Q. Influence of epoxy resin on the morphological and rheological properties of PBT/ABS blends compatibilized by ASMA. Polymer Engineering \& Science. 2007;47(11):1943-1950. DOI: 10.1002/pen.20913

14. Pellow-Jarman M, Hetem M. Comparison of the thermal degradation products of poly(butylene terephthalate) and flame retardant poly(butylene terephthalate) formulations using a pyrolysis FTIR cell. Polymer Degradation and Stability. 1995;47(3):413-421. DOI: 10.1016/0141-3910(95)00006-2 